Original Research

\title{
Motivasi Kepesertaan Mandiri BPJS di Era Universal Health Coverage Jaminan Kesehatan Nasional
}

\author{
Anita Dahliana ${ }^{1 *}$ \\ ${ }^{1}$ Fakultas Kedokteran, Universitas Surabaya, Surabaya-Indonesia \\ *corresponding author: anitadahliana@staff.ubaya.ac.id
}

\begin{abstract}
This research was conducted to determine the motivation of BPJS Health participants as independent participants. In this study, researchers used a motivational theory developed by Clayton Alderfer with three indicators namely Existence, Relatedness and Growth with a descriptive quantitative research approach with non-random sampling using a purposive method using conditions in selecting respondents ie respondents were outpatients in Specialist Poly Wiyung Hospital, Surabaya. The selected respondents were 43 people. The results of this study were the discovery of community motivation as independent health insurance participants.
\end{abstract}

Keywords: internal motivation, external motivation, existence, relatedness, growth, universal health coverage.

Abstrak-Penelitian ini dilakukan untuk mengetahui motivasi peserta BPJS Kesehatan sebagai peserta mandiri. Peneliti menggunakan teori motivasi yang dikembangkan oleh Clayton Alderfer dengan tiga indikator yaitu Existence, Relatedness dan Growth dengan pendekatan penelitian kuantitatif deskriptif. Teknik penga mbilan sampel non-random menggunakan cara purposive, yakni pemilihan responden menggunakan syarat tertentu (responden adalah pasien rawat jalan di Poli Spesialis RS Wiyung Sura baya). Responden yang dipilih berjumlah 43 orang. Hasil penelitian ini menunjukkan a danya motivasi masya rakat yang menjadi peserta mandiri jaminan kesehatan.

Kata kunci: motivasi internal, motivasi eksternal, existence, relatedness, growth, universal health coverage.

\section{PENDAHULUAN}

Pemerintah Indonesia bertanggung jawab atas pelaksanaan jaminan kesehatan masyarakat melalui Jaminan Kesehatan Nasional (JKN) bagi kesehatan perorangan. Usaha ke arah itu telah dirintis pemerintah dengan menyelenggarakan beberapa bentuk jaminan sosial di bidang kesehatan, diantaranya melalui PTASKES (Persero) dan PT Jamsostek (Persero) yang melayani antara lain pegawai negri sipil, penerima pensiun, veteran dan pegawai swasta. Pemerintah memberikan jaminan untuk masyarakat miskin dan tidak mampu, melalui Jaminan Kesehatan Masyarakat.

Pada tahun 2004, dikeluarkan Undang-Undang No. 40 tentang Sistem Jaminan Sosial Nasional (SJSN), yang mengamanatkan bahwa jaminan sosial wajib bagi seluruh penduduk termasuk Jaminan Kesehatan Nasional (JKN) melalui Badan Penyelenggara Jaminan Sosial (BPJS).

\section{Universal Health Coverage}

Pencapaian Universal Health Coverage (UHC) dilakukan melalui mekanisme asuransi sosial agar pembiayaan kesehatan dapat dikendalikan sehingga keterjaminan pembiayaan kesehatan menjadi pasti dan terus menerus tersedia yang pada gilirannya keadilan bagi seluruh rakyat Indonesia (sesuai sila ke-5 Pancasila) dapat terwujud.

Pada tahun 2014, BPJS kesehatan sudah mulai beroperasi. Pentahapan kepesertaan Jaminan Kesehatan dalam SJSN (Sistem Jaminan Sosial Nasional) dimulai dengan pengalihan peserta JPK Jamsostek, Jamkesmas, Askes PNS, TNI/Polri ke BPJS Kesehatan. Peserta Jamkesmas yang nantinya akan menjadi peserta yang iurannya dibayai pemerintah (PBI) berjumlah 86,4 juta jiwa yang dikelola oleh BPJS kesehatan pada tahun 2014. Di luar pengelolaan oleh BPJS kesehatan diperkirakan ada lebih dari 50 juta penduduk yang telah memiliki jaminan kesehatan tetapi dikelola dengan berbagai model. 


\section{Jaminan Kesehatan Nasional}

Jaminan Kesehatan Nasional (JKN) yang dikembangkan di Indonesia merupakan bagian dari sistem jaminan sosial nasional yang diselenggarakan dengan menggunakan mekanisme asuransi kesehatan sosial yang bersifat wajib (mandatory) berdasarkan Undang-Undang No.40 Tahun 2004 tentang SJSN dengan tujuan untuk memenuhi kebutuhan dasar kesehatan masyarakat yang layak diberikan kepada setiap orang yang telah membayar iuran (peserta BPJS mandiri) atau iurannya dibayar oleh pemerintah (PBI).

Reformasi menyeluruh program jaminan sosial bidang kesehatan dirasakan krusial karena peraturan pelaksanaan yang berlaku masih bersifat parsial dan tumpang tindih, manfaat program belum optimal, dan jangkauan program yang terbatas serta hanya menyentuh sebagian kecil masyarakat. Reformasi dilakukan tidak hanya dalam aspek pembiayaan tetapi juga reformasi dalam aspek layanan kesehatan.

Ada sekitar 36,8 persen penduduk Indonesia yang belum mempunyai jaminan kesehatan apapun, termasuk mereka yang bekerja di sektor informal. Hal ini menjadi tantangan tersendiri dalam perluasan jaminan kesehatan di Indonesia karena struktur kelompok pekerja di sektor informal yang relatif tinggi dibanding jumlah pekerja di sektor formal. Secara umum pekerja di sektor informal memiliki tingkat konsumsi yang lebih tinggi dinbanding dengan tingkat pendapatannya sehingga apabila pekerja/anggota keluarga jatuh sakit maka pekerja/anggota keluarga akan kehilangan produktivitas dan/atau kehilangan sumber pendapatan yang memudahkan mereka untuk jatuh miskin. Oleh karena itu, bantuan pembiayaan kesehatan sangat dibutuhkan untuk semua kelompok masyarakat miskin dan rentan.

Cara penetapan sasaran program jaminan sosial bidang kesehatan juga merupakan catatan tersendiri karena belum menggunakan metodologi baku sehingga berdampak pada keluhan salah sasaran yang cukup besar (tingginya exclusion error dan inclusion error) dan kebocoran ke keluarga/kolega yang tidak miskin/rentan. Data Susenas tahun 2009 menunjukkan tingkat ketepatan sasaran hanya sekitar 33 persen dari target penerima seharusnya. Di samping itu rendahnya tingkat kesadaran akan manfaat Jamkesmas membuat peserta belum secara optimal menggunakan layanan di fasilitas kesehatan.

Untuk mewujudkan jaminan kesehatan bagi seluruh penduduk atau jaminan kesehatan semesta sesuai amanat Undang-Undang Dasar 1945 dan Undang-Undang No. 40 tahun 2004 tentang Sistem Jaminan Kesehatan Nasional (SJSN), pemerintah meluncurkan program Jaminan Kesehatan Nasional (JKN) pada awal tahun 2014 dengan target bahwa kepesertaan semesta akan tercapai dalam jangka waktu 5 tahun. Artinya setiap individu wajib menjadi peserta dan terlindungi dalam program asuransi kesehatan sosial nasional. Jaminan kesehatan semesta ini bertujuan untuk meningkatkan akses masyarakat pada pelayana kesehatan yang komprehensif, bermutu dan merata bagi seluruh penduduk Indonesia.

\section{Badan Penyelenggara Jaminan Sosial (BPJS)}

Badan penyelenggara Jaminan sosial atau BPJS kesehatan adalah badan hukum publik yang berfungsi menyelenggarakan program jaminan kesehatan bagi seluruh masyarakat Indonesia termasuk warga asing yang bekerja paling singkat 6 bulan di Indonesia. Peserta BPJS terdiri dari peserta bantuan iur yang selanjutnya disebut dengan peserta $\mathrm{PBI}$, yang terdiri dari fakir miskin dan orang tidak mampu dan golongan non PBI atau peserta dari peralihan ASKES yang elanjutnya disebut sebagai peserta mandiri BPJS.

Masyarakat kota Surabaya yang belum terlindungi oleh jaminan pembiayaan kesehatan perlu diupayakan agar mereka bersedia secara mandiri menjadi peserta jaminan kesehatan. Dengan adanya jaminan kesehatan maka mereka dapat terhindar dari risiko bahaya berobat yang mahal dan terhindar dari biaya pengobatan di luar kemampuannya yang mengakibatklan mereka jatuh miskin karena kehilangan penghasilan selama sakit atau bahkan terpaksa harus menjual asset produktif untuk biaya berobat.

Di sisi lain dengan mengupayakan agar masyarakat kota Surabaya yang belum 
mempunyai jaminan kesehatan bersedia secara mandiri menjadi peserta jaminan kesehatan, maka hal ini juga merupakan upaya untuk mempercepat peluasan kepesertaan JKN menuju pencapaian Universal Coverage yang diharapkan dapat terlaksana pada tahun 2019. Untuk mengembangkan upaya agar masyarakat bersedia secara mandiri menjadi peserta jaminan kesehatan maka perlu diketahui sebel umnya mengenai motivasi masyarakat menjadi peserta mandiri jaminan kesehatan.

\section{Motivasi}

Motif seringkali diistilahkan sebagai dorongan. Dorongan atau tenaga tersebut merupakan gerak jiwa dan jasmani untuk berbuat sehingga motif tersebut merupakan driving force yang menggerakkan manusia untuk bertingkah laku dan di dalam perbuatannya itu mempunyai tujuan tertentu. Motivasi secara sederhana dapat diartikan sebagai keinginan pada individu yang mampu merangsang untuk melakukan tindakan. Faktor pendorong terpenting manusia melakukan tindakan atau aktivitas adalah karena adanya kebutuhan atau untuk membawanya pada keadaan kehidupan yang lebih baik atau lebih memuaskan daripada keadaan sekarang. Jadi motivasi terbentuk karena adanya kebutuhan yang harus dipenuhi.

Proses dasar motivasi adalah sebagai berikut :

1. Proses motivasional berawal dari identifikasi individu terhadap kebutuhannya yang belum terpenuhi. Kebutuhan adalah kekurangan yang dialami oleh individu pada suatu waktu tertentu, kekurangan ini dapat bersifat psikologis dan fisiologis.

2. Kebutuhan yang belum terpenuhi menciptakan ketegangan karena individu tidak nyaman dengan kekurangan yang dirasakannya.

3. Ketegangan ini memicu idividu untuk memenuhi kebutuhannya sehingga dapat mengurangi atau menghilangkan ketegangan tersebut dan mencapai tujuanya.

4. Untuk mengatasi kekurangannya, seseorang berusaha untuk bekerja pada bidang yang dapat memenuhi kebutuhannya.

5. Hasil dari usaha tersebut adalah pemenuhan kebutuhan

6. Jika telah mendapatkan hasil maka ketegangan seseorng akan berkurang dan ia akan mengevaluasi kebutuhannya.

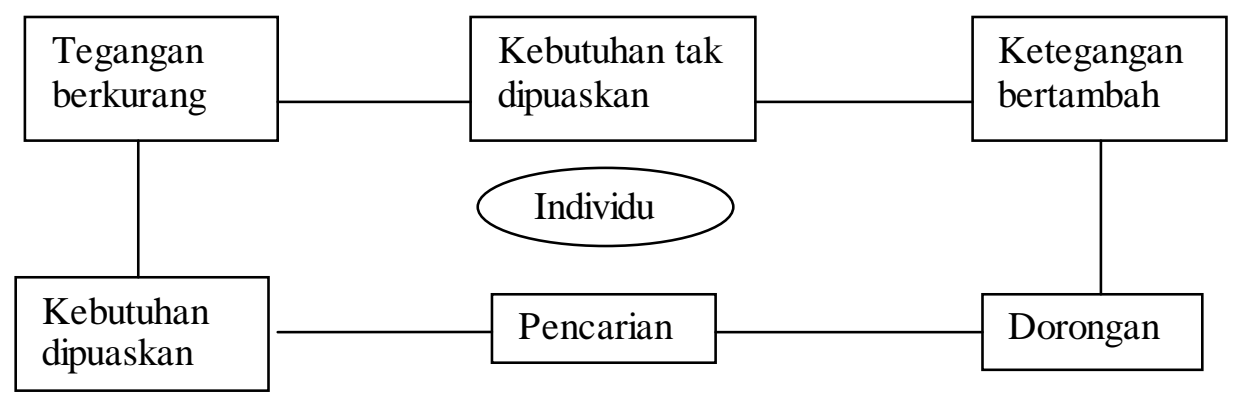

Gambar 1. Proses motivasi.

Setiap tindakan yang dilakukan oleh manusia selalu dimulai dengan motivasi (niat). Menurut Wexley dan Yulk (dalam As'ad 1987), motivasi adalah pemberian atau penimbulan motif, dapat pula diartikan hal atau keadaan menjadi motif. Sedangkan menurut Mitchell (dalam Winardi 2002), motivasi mewakili proses psikologika yang menyebabkan timbulnya, diarahkannya dan terjadinya persistensi kegiatan sukarela (motivasi) yang diarahkan menuju tujuan tertentu.

Morgan (dalam Soemanto, 1987) mengemukakan bahwa motivasi bertalian dengan tiga hal yang sekaligus merupakan aspek dari motivasi yaitu keadaan yang mendorong tingkah laku (motivating states), tingkah laku yang didorong oleh keadaan tersebut (motivated behavior) dan tujuan tingkah laku tersebut (goal or end s of such behavior). Mc Donals (dalam Soemanto, 1987) mendefinisikan motivasi sebagai perubahan tenaga di dalam diri seseorang yang ditandai dengan dorongan efektif dan reaksi mencapai tujuan.

Berikut ini adalah faktor yang memengaruhi motivasi. 
1. Faktor internal ( berasal dari dalam individu), terdiri atas:

a. Persepsi individu. Seseorang termotivasi atau tidak untuk melakukan sesuatu tergantung pada proses kognitif berupa persepsi. Persepsi seseorang akan mendorong dan mengarahkan perilaku seseorang untuk bertindak.

b. Harga diri dan prestasi. Faktor ini mendorong atau mengarahkan individu untuk berusaha agar menjadi pribadi yang mandiri, kuat, memperoleh kebebasan, mendapatkan status tertentu dalam lingkungan masyarakat serta dapat mendorong individu untuk berprestasi.

c. Harapan (adanya harapan di masa depan). Harapan merupakan informasi objektif dari lingkungan yang memengaruhi sikap dan perasaan subjektif seseorang. Harapan merupakan tujuan dari perilaku.

d. Kebutuhan. Manusia dimotivasi oleh kebutuhan untuk menjadikan dirinya sendiri yang berfungsi secara penuh sehingga mampu meraih potensinya secara total. Kebutuhan akan mendorong dan mengarahkan seseorang untuk mencari dan menghindari, mengarahkan dan memberi respons terhadap tekanan yang dialaminya.

e. Kepuasan kerja. Kepuasan kerja ini merupakan suatu dorongan afektif yang muncul dalam diri seseorang untuk mencapai goal atau tujuan yang diinginkan dari suatu perlaku.

2. Faktor eksternal (berasal dari luar individu):

a. Jenis dan sifat pekerjaan. Dorongan untuk bekerja pada jenis dan sifat pekerjaan tertentu sesuai dengan objek pekerjaan yang tersedia dan akan mengarahkan individu untuk menentukan sikap atau pilihan pekerjaan yang akan ditekuni. Kondisi ini juga dapat dipengaruhi oleh sejauhmana imbalan yang dimiliki oleh objek pekerjaan yang dimaksud.

b. Kelompok kerja tempat individu bergabung. Kelompok kerja atau organisasi tempat individu bergabung dapat mendorong atau mengarahkan perilaku individu dalam mencapai suatu tujuan perilaku tertentu. Peranan kelompok atau organisasi ini dapat membantu individu mendapatkan kebutuhan akan nilai kebenaran, kejujuran, kebajikan, serta dapat memberikan arti bagi individu itu sehubungan dengan kiprahnya dalam kehidupan sosial.

c. Situasi lingkungan. Setiap individu terdorong untuk berhubungan dengan rasa mampunya dalam melakukan interaksi secara efektif dengan lingkungannya.

d. Sistem imbalan yang diterima. Imbalan merupakan karakteristik atau kualitas dari objek pemuas yang dibutuhkan oleh seseorang yang dapat memengaruhi motivasi atau dapat mengubah arah tingkah laku dari satu objek ke objek lain yang mempunyai nilai imbalan yang lebih besar. Sistem pemberian imbalan dapat mendorong individu untuk berperilaku dalam mencapai tujuan, perilaku dipandang sebagai tujuan sehingga ketika tujuan tercapai maka timbul imbalan.

\section{Teori Existence Related Growth}

Penelitian motivasi masyarakat menjadi peserta mandiri jaminan kesehatan ini menggunakan teori motivasi yang dikembangkan oleh Clayton Alderfer dengan tiga kebutuhan pokok yaitu existence, relatedness, dan growth. Kebutuhan existence merupakan kebutuhan nyata setiap orang untuk mempertahankan dan melanjutkan eksistensinya. Hal ini sesuai dengan kodrat manusia untuk memenuhi kebutuhan hidupnya.

Peneliti membagi kelompok kebutuhan peserta mandiri jaminan kesehatan menjadi tiga kelompok yaitu kebutuhan primer, kebutuhan sekunder, kebutuhan tersier. Kebutuhan relatedness merupakan kebutuhan yang tercermin pada sifat dasar manusia sebagai insan sosial yang identik dengan kebutuhan pada interaksi. Kebutuhan growth merupakan hubungan 
yang pada dasarnya tercermin pada keinginan seseorang untuk bertumbuh dan berkembang. Dalam konteks penelitian ini, maka pada Existence, kebutuhan primer adalah jaminan pelayanan kesehatan; kebutuhan sekunder adalah jaminan pembiayaan; kebutuhan tersier adalah fasilitas kesehatan termasuk saran dan prasarana.

Penelitian ini bertujuan ingin mengetahui motivasi peserta BPJS dalam mengikuti program BPJS Kesehatan kategori peserta mandiri (Studi kasus pasien rawat jalan Rumah Sakit Wiyung Sejahtera).

\section{METODE}

\section{Kerangka Konsep Penelitian}

Kerangka konseptual dalam penelitian ini digambarkan sebagai berikut.

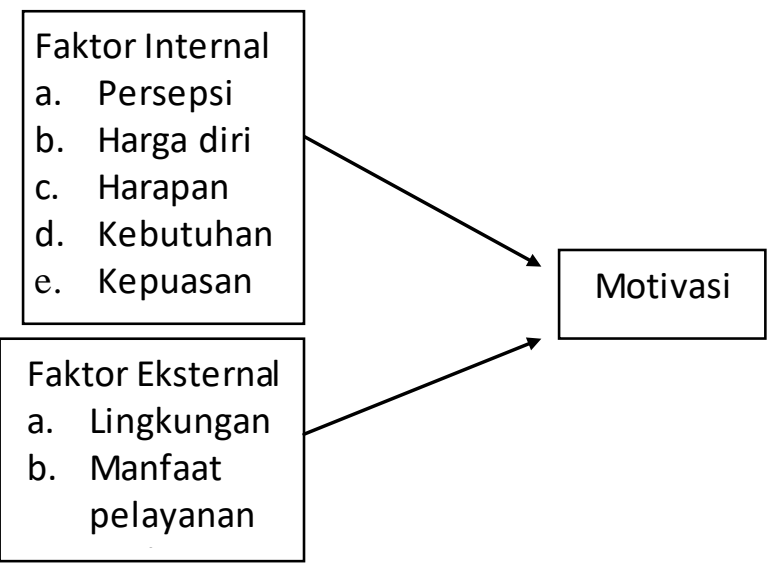

Gambar 2. Kerangka konsep penelitian.

Penelitian menggunakan metode deskriptif dengan pendekatan kualitatif. Desain cross sectional digunakan untuk menganalisis faktor yang memengaruhi motivasi kepesertaan mandiri BPJS di Era Universal Health Coverage Jaminan Kesehatan Nasional. Sumber data primer diperoleh langsung dari responden dengan cara pengamatan, wawancara, dan dokumentasi. Data sekunder berupa data primer yang diperoleh dari pihak lain atau data primer yang telah diolah atau disajikan.

Analisis statistik penelitian ini menggunakan uji $t$ dan regresi linear. Adapun taraf kemaknaan yang digunakan adalah alfa 0,05. Pada tahapan uji t dilakukan analisis komparasi mean dari setiap kelompok data. Pada tahapan ini digunakan berbagai software statistik dan data analitik, seperti Microsoft Office Excell Professional, SPSS IBM, dan Microsoft Power BI. Adapun uji regresi dilakukan simultan pada seluruh kelompok data.

Populasi dan sampel penelitian adalah pasien poli penyakit dalam (rawatjalan) Rumah Sakit Wiyung Sejahtera Kota Surabaya Provinsi Jawa Timur sejumlah 43 orang.

Teknik sampling yang digunakan adalah sample random sampling, yaitu teknik pengambilan sampel yang dilakukan secara acak sehingga setiap kasus atau elemen dalam populasi memiliki kesempatan yang sama besar untuk dipilih sebagai sampel penelitian.

\section{HASIL DAN BAHASAN}

Peserta BPJS mandiri yang menjadi subjek penelitian ini adalah pasien Rumah Sakit Wiyung Sejahtera yang sedang melakukan kunjungan rawat jalan di poli spesialis Penyakit Dalam. Pasien yang melakukan kunjungan rawat jalan di poli spesialis merupakan pasien rujukan dari PPK I di wilayah Surabaya Barat.

Peserta BPJS yang melakukan kunjungan rawat jalan di Poli Penyakit Dalam terdiri atas peserta BPJS mandiri dan peserta BPJS penerima bantuan iuran. Kemudian peserta BPJS mandiri diberikan kuesioner. Dari hasil penelitian diketahui jumlah peserta BPJS mandiri berdasarkan jenis kelamin, usia, pendidikan, pekerjaan, pendapatan, sumber informasi, kebutuhan peserta terhadap BPJS, dan motivasi peserta untuk menjadi peserta mandiri BPJS. 


\section{Jenis Kelamin}

Dari hasil penelitian diketahui bahwa jumlah peserta BPJS mandiri berdasarkan jenis kelamin tidak terdapat perbedaan yang cukup signifikan antara peserta BPJS mandiri yang lakilaki dan perempuan.

Tabel 1

Penilaian Berdasarkan Jenis Kelamin Responden

\begin{tabular}{llcc}
\hline No & Jenis Kelamin & Frek & \% \\
\hline 1 & Laki - laki & 19 & 44,2 \\
2 & Perempuan & 24 & 55,8 \\
\hline & Jumlah & 43 & 100 \\
\hline
\end{tabular}

Usia

Penelitian berdasarkan usia dilakukan untuk mengetahui tingkat kebutuhan terhadap pelayanan kesehatan sesuai dengan karakteristik penyakit berdasarkan usia peserta. Berdasarkan Tabel 2 diketahui bahwa jumlah responden paling banyak ada pada rentang usia $\geq$ 50 tahun. Hal ini disebabkan kunjungan terbanyak pada kasus geriatri dan penyakit kronis.

Tabel 2

Penilaian Berdasarkan Usia Responden

\begin{tabular}{crcc}
\hline No & Usia & Frek & $\%$ \\
\hline 1 & $20-29$ tahun & 6 & 13,9 \\
2 & $30-39$ tahun & 9 & 20,9 \\
3 & $40-49$ tahun & 12 & 27,9 \\
4 & $\geq 50$ tahun & 16 & 37,2 \\
\hline \multicolumn{2}{l}{ Jumlah } & 43 & 100 \\
\hline
\end{tabular}

\section{Pendidikan}

Penilaian terhadap pendidikan peserta BPJS dilakukan untuk mengetahui tingkat pemahaman terhadap regulasi bahwa seluruh warga Negara. Penilaian terhadap pendidikan peserta BPJS dilakukan untuk mengetahui tingkat pemahaman terhadap regulasi bahwa seluruh warga negara Indonesia harus mengikuti program BPJS kesehatan dan untuk mengetahui tingkat kesadaran peserta terhadap kesehatannya.

Tabel 3

Penilaian Berdasarkan Pendidikan Responden

\begin{tabular}{clcc}
\hline No & \multicolumn{1}{c}{ Pendidikan } & Frek & \% \\
\hline 1 & SLTP & 11 & 25,6 \\
2 & SLTA & 15 & 34,9 \\
3 & Diploma/S1/S2/S3 & 13 & 30,2 \\
4 & Lain - lain & 4 & 9,3 \\
\hline & Jumlah & 43 & 100 \\
\hline
\end{tabular}

\section{Pendapatan}

Penilaian terhadap pendapatan dilakukan untuk mengetahui kemampuan peserta BPJS mandiri untuk melakukan pembayaran premi. 
Tabel 4

Penilaian Berdasarkan Pendapatan Responden

\begin{tabular}{clcc}
\hline No & \multicolumn{1}{c}{ Pendapatan } & Frek & $\%$ \\
\hline 1 & $<1$ juta & 2 & 4,6 \\
2 & $1-5$ juta & 23 & 53,5 \\
3 & $5-10$ juta & 13 & 30,2 \\
4 & $>10$ juta & 5 & 11,6 \\
\hline & Jumlah & 43 & 100 \\
\hline
\end{tabular}

\section{Sumber Informasi}

Penilaian responden terhadap sumber informasi yang diterima untuk mengatahui informasi pertama yang diketahui peserta BPJS mandiri.

\section{Tabel 5}

Penilaian Berdasarkan Sumber Informasi

\begin{tabular}{clcc}
\hline No & Sumber informasi & Frek & $\%$ \\
\hline 1 & Keluarga & 7 & 16,2 \\
2 & Tetangga & 6 & 13,9 \\
3 & Teman & 8 & 18,6 \\
4 & TV / radio & 17 & 39,5 \\
5 & Koran / Brosur & 5 & 11,6 \\
\hline & Jumlah & 43 & 100 \\
\hline
\end{tabular}

\section{Kebutuhan Peserta Terhadap BPJS Mandiri}

Penilaian responden tentang kebutuhan peserta BPJS mandiri dilakukan untuk mengetahui tingkat kebutuhan peserta terhadap BPJS.

Tabel 6

Penilaian Tentang Kebutuhan Responden Sebagai Peserta BPJS Mandiri

\begin{tabular}{cccc}
\hline No & Kebutuhan & Frek & \% \\
\hline 1 & Jaminan pembiayaan & 18 & 41,9 \\
2 & Pelayanan kesehatan & 13 & 30,2 \\
3 & Akses lokasi ke RS & 12 & 27,9 \\
\hline & Jumlah & 43 & 100 \\
\hline
\end{tabular}

\section{Motivasi Sebagai Peserta BPJS Mandiri}

Penilaian responden tentang motivasi dilakukan untuk mengetahui motivasi peserta dalam mengikuti program BPJS Kesehatan dengan menggunakan biaya sendiri.

Tabel 7

Penilaian Tentang Motivasi Responden Sebagai Peserta BPJS Mandiri

\begin{tabular}{cccc}
\hline No & Motivasi & Frek & \% \\
\hline 1 & Anjuran keluarga & 11 & 25,6 \\
2 & Kesadaran sendiri & 32 & 74,4 \\
\hline & Jumlah & 43 & 100 \\
\hline
\end{tabular}




\section{SIMPULAN}

Memperhatikan hasil dan bahasan dalam penelitian ini, maka dapat disimpulkan bahwa motivasi peserta BPJS untuk mengikuti program BPJS Kesehatan dengan biaya sendiri berasal dari kesadaran peserta. Faktor yang memengaruhi motivasi peserta BPJS mandiri tersebut adalah karena adanya jaminan pembiayaan, kebutuhan terhadap pelayanan kesehatan, dan kemudahan akses pelayanan Pemberi Pelayanan Kesehatan (PPK).

\section{BIBLIOGRAFI}

Hasan, I 2002, Metodologi penelitian dan Aplikasinya, Ghalia Indonesia, Bogor. Maslow, AH 2010, Motivation and personality, Rajawali, Jakarta.

Notoatmodjo, S 2003a, Ilmu kesehatan masyarakat, Rineka Cipta, Jakarta.

Notoatmodjo, S 2003b, IImu kesehatan masyarakat: Prinsip-prinsip dasar, Rineka Cipta, Jakarta.

Notoatmodjo, S 2007a, Kesehatan masyarakat: ilmu dan seni, Rineka Cipta, Jakarta.

Notoatmodjo, S 2007b, Promosi kesehatan dan ilmu perilaku, Rineka Cipta, Jakarta.

Notoatmodjo, S 2010, Metodologi penelitian kesehatan. Rineka Cipta, Jakarta.

Sugiyono 2011, Metode penelitian kuantitatif kualitatif dan R\&D, 1st ed., Alfabeta, Bandung. Widiana, IGR 2016, Aplikasi statistik pada penelitian kedokteran, EGC, Jakarta. 